\title{
A systematic review of blue carbon as an approach for Eco-DRR: current gap and future research
}

\author{
Taiwo Ogunwumi ( $\nabla$ taiwoogunwumi@yahoo.com ) \\ United Nations University, Institute for Environment and Human Security \\ Margarethe-Elizabeth Graves Armstrong \\ United Nations University, Institute for Environment and Human Security
}

\section{Research Article}

Keywords: Blue Carbon, Wetlands, Mangroves, Seagrasses, Ecosystem-based disaster risk reduction, Coastal Risk, GIS, Sustainable Ecosystem Management

Posted Date: January 7th, 2022

DOI: https://doi.org/10.21203/rs.3.rs-1128889/v2

License: (1) This work is licensed under a Creative Commons Attribution 4.0 International License. Read Full License 


\section{Abstract}

Blue carbon ecosystems (BCEs), such as wetlands, marshes, mangroves, and seagrasses, warrant increased attention for their abilities to protect life, property, and environments locally and globally. BCEs

serve as both buffers reducing coastal hazards and carbon sinks storing 'blue' carbon in aquatic plant life and soils. While research exists on BCE functions and benefits, their global diversity necessitates a collection of localized research investigating the unique dynamics and histories of distinct BCEs. The historic degradation of coastal ecosystems proves the need for purposeful, well-informed, sustainable ecosystem management to conserve and restore BCEs. We conducted a systematic literature review to understand the existing body of research on synergies between BCEs and ecosystem-based disaster risk reduction (Eco-DRR). We investigated how prior research employed various research methods, discussed key aspects of sustainable land management, and considered geographic locations and scales. We discovered localized case studies have incredible insights on the efficacy of BCEs along with contextspecific strategies for sustainable ecosystem management. However, as these case studies are not plentiful and are concentrated in North America and Asia, they do not account for the diversity of BCEs. We suggest increased support for localized research on the benefits and implementation of BCEs as EcoDRR measures.

\subsection{Introduction}

Healthy coastal ecosystems are vital to the preservation and safety of individuals, societies, and environments around the world both because of the role they play in climate change mitigation and because of their capacity to reduce risk of disaster caused by tides, storms, and floods. Though blue carbon ecosystems are ubiquitous in coastal regions, the term was only coined in 2009 to describe ecosystems like mangroves, salt marshes, seagrasses, and various wetlands, which abound in coastal plants that store and sequester organic compounds like carbon dioxide, thereby preventing the release of carbon into the atmosphere and mitigating climate change (Nellemann et al., 2009, Mcleod et al., 2011, Pendleton et al., 2012). The carbon is stored both in the living aquatic plants and in the soil that the plants generate as they decay and settle on the ocean floor. In seagrass meadows for instance, $95 \%$ of stored carbon exists within the meadow soils (US Environmental Protection Agency, 2016). While carbon sequestration contributes to human and environmental security by combatting long-term trends in climate change, these ecosystems also serve as a natural buffer zone to storm damage, flooding, and coastal erosion (Sutton-Grier et al., 2014, Shepard et al., 2011). In comparison to grey-infrastructure disaster risk reduction measures like seawalls, blue carbon is an attractive investment because it is costeffective and it has many co-benefits such as creating sustainable livelihood opportunities, fostering biodiversity, and filtering agricultural and industrial waste (Nellemann et al., 2009, Grimsditch et al., 2013).

Through a review of existing academic literature, this paper will investigate the state of academic literature around the role that blue carbon ecosystems can play in ecosystem-based disaster risk reduction (Eco-DRR) by analyzing 1 ) which academic disciplines are contributing to research on the 
synergies between blue-carbon ecosystems and Eco-DRR, 2) what aspects of this topic these researchers are concerned with, 3)what methods they are using, and 4) where the research is concentrated. This will begin with an introduction to basic concepts and definitions of blue carbon ecosystems and Eco-DRR measures, as well as their intersections. Secondly, this paper will detail the methods used to systematically identify, refine, and analyze a collection of relevant literature. Section three discusses the statistical trends and major themes present in this body of research, followed by a discussion section, which will detail the questions that we were not able to answer in this literature review due to research gaps as well as our own limitations. Finally, section five will conclude the paper, summarizing the existing body of research and suggesting opportunities for scholars to further explore the potential of blue carbon ecosystems in disaster risk reduction.

\subsection{BACKGROUND AND DEFINITIONS}

\subsubsection{Ecosystem-Disaster Risk Reduction (Coastal ecosystem-DRR)}

Ecosystem-based disaster risk reduction (Eco-DRR) is a series of sustainable environmental management strategies that aim to leverage the regulatory functions of ecosystems for the purpose of preventing, mitigating, or diminishing the impacts of disasters (Estrella and Saalismaa, 2013, UNEP, 2020). While standard disaster risk reduction measures attempt to minimize the likelihood and severity of system shocks by improving capacities to prepare, manage, respond, and recover, Eco-DRR attempts to contribute to this effort by recognizing the capacity of naturally occurring systems to handle such shocks (Sudmeier-Rieux and Ash, 2009). Eco-DRR relies on strategies that are simultaneously innovative in their approaches to conservation and restoration, yet reliant on often ancient ecosystems, which are complex webs of flora, fauna, geological structures and hydrological bodies (Estrella and Saalismaa, 2013, Millennium Ecosystem Assessment, 2005).

As blue carbon ecosystems are uniquely composed to thrive in or near sometimes tumultuous bodies of water, wetland ecosystems like mangroves, seagrasses, and salt marshes provide excellent Eco-DRR measures because they are often effective in absorbing tides and storm surges to prevent flooding and coastal erosion (Campbell et al., 2009). The dynamics of this can be seen in Figure 1, and are described in more detail with regards to specific types of blue carbon ecosystems in the following sections.

\subsubsection{Wetland}

'Wetland' is a blanket term used to refer to ecosystems such as coastal wetlands, peatland, mangrove forests, estuarine wetlands, and marshes, which have waterlogged soils, high water levels, and plants adapted for such conditions (Guo et al., 2017, NOAA, 2021). While wetland is not synonymous with blue carbon ecosystems, wetlands do serve as blue carbon ecosystems and are often referenced throughout literature that does not explicitly identify them as blue carbon ecosystems. As is the case with blue carbon ecosystems, wetlands provide many valuable ecosystem services such as improving water 
quality, preventing coastal erosion, recharging groundwater, and disaster risk reduction via flood and drought prevention (Guo et al., 2017).

\subsubsection{Mangroves}

Mangroves describe coastal forests that contain shrubs and trees, which have aerial roots that are remarkable in their ability to capture and store atmospheric gasses at a rate of four times that of terrestrial forests (Siikamaki et al., 2013, Donato et al., 2011). Additionally, these root systems diminish the force of tides and storm surges that otherwise result in coastal erosion, flooding, and associated destruction (Siikamäki et al., 2013). Through these ecosystem services combined with co-benefits like filtering pollutants and supporting sustainable livelihoods, it is estimated that mangroves provide \$1.6 billion (USD) in annual value globally (Blue Carbon Initiative, 2010). As an aquatic forest ecosystem, mangroves are primarily found in estuaries, deltas, and coastal lagoons. The current global coverage of mangroves is estimated to be $139,170 \mathrm{~km}$ (Giri et al., 2011).

\subsubsection{Seagrasses}

Seagrasses are marine plants that are unique as the only plants able to survive while completely submerged underwater (Siikamaki et al., 2013). While they live, pollinate, and reproduce underwater, they are more concentrated in the shallow coastal areas that have enough sunlight to enhance their growth, so they typically grow into semi-aquatic meadows (TheWildlifeTrust, 2021). Like mangroves, seagrasses have a huge capacity to store carbon both in living plants and in the soils they create, as well as utility in disaster risk reduction. They filter pollutants and their roots and lush soil help stabilize seabeds, thereby decreasing the force of waves as they approach coastlines. This minimizes coastal erosion and destruction caused by storms and hurricanes. According to the United Nations Environment Programme (UNEP), seagrass ecosystems cover $319,000 \mathrm{~km} 2$ of the globe, with a concentration of $70 \%$ located in tropical areas between the Tropic of Cancer and the Tropic of Capricorn (UNEP-WCMC, 2005).

\subsubsection{Salt Marshes}

Like seagrass and mangroves, salt marshes are effective at capturing and storing carbon within plants and sediment as well as protecting land from storm surges and sea-level rise (TheWildlifeTrust, 2021). Salt marshes are a type of wetland that forms in low-energy inter-tidal zones inside estuaries and bays (Leonardi et al., 2018). Salt Marshes are special because due to high tides, plants are able to adapt and cope with high salinity and regular submersion (Mcowen, 2017). This combination of specialized vegetation and the location at pivotal water ingress points equips salt marshes to buffer against the impact of tides and storms (Leonardi et al., 2018). Salt marshes cover roughly 51,000 km2 worldwide, primarily outside of the tropics in the North Atlantic (Chmura et al., 2003, Mcowen, 2017).

\subsection{Methodology}


This literature review used the Clarivate Web of Science database to conduct and screen keyword searches in order to select peer-reviewed research papers which dealt both with blue carbon and with EcoDRR. To better ensure the relevance of the final search term selection, we first conducted a thorough, nonsystematic literature search with google scholar to identify relevant concepts and terms.

To explore the relationship between blue carbon and Eco-DRR, selected research papers had to include both concepts. Thus, the search on the Clarivate Web of Science database used an iterative search process with two separate groups of terms. Group 1 included terms related to blue carbon ecosystems, which were identified through the previously mentioned non-systematic literature search. Through this initial literature search, it was clear that researchers discussing similar topics may use different terms. For instance, instead of requiring all publications to include "blue carbon", an "OR" operator was used, thereby considering papers describing types of blue carbon, such as salt marshes, that may not have been explicitly referred to as blue carbon within the papers. Group 2 included terms related to Eco-DRR, which were selected based on terms and examples from a publication from the International Union for the Conservation of Nature (IUCN) on Nature-based Solutions (NbS), which encompasses Eco-DRR (CohenSchachem et al. 2016). However, Group 2 terms are limited to those that explicitly addressed disaster risk, excluding terms like "Nature-based Solutions" and "climate adaptation", which yielded papers concerned with the capacity of blue carbon ecosystems to serve as carbon sinks rather than the capacity to aid in disaster risk reduction. There were no limitations on the year of publication. However, research around this topic became more common after the term "blue carbon" was coined in 2009. Therefore, even the broadest searches returned primarily papers published in 2009 or later (Bertram et al. 2021). Additionally, the search was limited to English-language publications.

Below are the final terms for the two search groups:

- Group 1: "Blue Carbon" OR "Coastal Ecosystem" OR "Salt Marsh*" OR "Seagrass*" OR "Mangrove*" OR "Wetland*" OR "Coastal Marsh*"

Group 2: "Ecosystem Disaster Risk Reduction" OR "Disasters" OR "DRR" OR "Hazard Mitigation" OR "Risk Management" OR "Risk Reduction" OR "Ecosystem-based Mitigation" OR "Risk Mitigation"

The first search, which included only blue carbon terms from group one, returned 84,890 results. The second search paired terms from Group 1 with those from Group 2 using an "AND" operator, ensuring that each selected source had at least one term from Group 1 and one term from Group 2. This returned 725 results, which were then further refined by a screening for publications that had the terms either in the title or abstract. This abstract and title search yielded 212 results. The remaining 212 papers were screened through a process of reading abstracts and titles to identify thematically irrelevant papers (ex: "Novel miniature mobile cardiac catheterization laboratory for critical cardiovascular disease following natural disasters: a feasible study"). The combination of terms from Group 1 and 2 also returned a number of publications with disaster assessments cataloging the effects of disasters such as oil spills and typhoons on blue carbon ecosystems. As this study is interested in how blue carbon ecosystems are used as a method of prevention and mitigation, we elected to eliminate disaster assessment publications in 
the manual screening process. This screening process culminated in 53 papers that addressed the relationship between blue carbon ecosystems and Eco-DRR.

Following this selection, was a coding process, in which researchers carefully read and analyzed each of the 53 articles. This process led to the exclusion of an additional 13 papers which, within the context of our study, did not place adequate focus on the synergies between blue carbon ecosystems and Eco-DRR. The final selection of 40 papers was then coded to analyze the following variables: authorship; year of publication; Publishing Journal; whether the publication was open access; study location (if applicable); study scale (if applicable); study method; blue carbon terms referenced; themes discussed in the paper. This information is aggregated in Table 1, which can be seen as an appendix item.

As a supplement to the manual process of thematic coding, the 40 papers were processed through Leximancer, a text analytics software that identifies key terms and themes to produce conceptual maps, providing an overview of a text or a body of texts (Leximancer, 2021). While leximancer is an automated software, the concept map generation did require a degree of manual input and modification. For instance, certain terms such as "doi", "fig", and "table", were removed from the initial identification of terms. While these terms likely appeared in nearly every publication, they represent formatting rather than conceptual themes. Another modification was the merging of concepts that appeared multiple times through pluralization or nominalization (ex: 'flood', 'floods', 'flooding'). One limitation of Leximancer is that it only identifies single-word concepts. However, it offers the option of compounding concepts, which was necessary our analysis because many central concepts, such as 'salt marsh', 'risk assessment', or 'disaster risk reduction' are multi-word concepts. Through this process, 118 terms were identified, which Lexigram then used to generate a concept map displaying how they cluster and relate to each other throughout the body of texts.

\subsection{Results}

\subsection{Data Analysis}

Of the 40 publications reviewed in this study, $65 \%$ presented original research, while $35 \%$ were reviews centered on pre-existing research. Throughout the body of texts, a variety of research methods were employed, including hazard modeling, risk assessments, cost-benefit analyses, economic impact assessments, community surveys, and interviews. Methods involving Geographic Information Systems (GIS) appeared in $40 \%$ of papers reviewed, including papers with a variety of disciplines and research goals.

Each paper referenced at least one of the four types of blue carbon ecosystem (wetlands, mangroves, seagrasses, salt marshes) identified in the introduction of this review, with nine papers (22.5\%) referencing at least two. The most frequently referenced category was wetlands, which eighteen papers (45\%) discussed. Ten papers (25\%) discussed mangroves, while six (15\%) discussed salt marshes and four $(10 \%)$ discussed seagrasses. 
The papers in this study presented research focused at different spatial scale scales ranging from the Community/municipality level to the global level. The majority were tied to a specific geographic location with only five papers (12.5\%) addressing Eco-DRR and blue carbon at a global scale. An additional four papers $(10 \%)$ discussed generalized concepts for which a location was not necessary (ex: environmental processes, technologies, and engineering solutions). The remaining thirty-one papers included studies in sixteen different counties, the distribution for which is depicted in Figure 6. Of these studies, two were on a multi-national scale, eight were on a national scale, ten were on a regional scale, and eight were on a local.

Though this review placed no limitations on the year of publication, the query returned no paper released prior to 2006 and only three papers in or before 2009. This is unsurprising because the term "blue carbon" was coined in 2009, at which point interest and understanding of blue carbon increased (Bertram et al., 2021). Due to this continued growth, $77.5 \%$ of documents reviewed were published in 2016 or later. Though there appears to be a dip in publications in 2021, this is likely misleading as this review was conducted in 2021, likely before the publication of additional papers. This trend of growing interest and research can be seen in Figure 9, which shows publications per year. The papers were published by 31 distinct journals and over half (21) of the papers were open source. The most common journals were Frontiers in Marine Science with four entries, the International Journal of Disaster Risk Reduction with three entries, and PLoS ONE with three entries.

Through the close reading during the coding process, the papers were categorized according to major themes in methods, key concerns, analysis, or discussion. Sixteen papers (40\%) employed at least one method of GIS. Twenty-four papers (60\%) detailed either the gravity or the causes of blue carbon ecosystem degradation. Twenty-nine papers (72.5\%) discussed the importance or methods of conservation (45\%), restoration (52.5\%), or establishment (7.5\%) of blue carbon ecosystems. Discussions of economic factors appeared in fifteen papers (37.5\%), nine of which conducted economic assessments such as cost-benefit analysis or economic impact assessments. Twenty-three (57.5\%) papers detailed policy suggestions or implications of their respective research.

\subsection{Literature Synthesis}

\subsubsection{Using Geographical Information System to analyse Blue Carbon for Eco-DRR}

The study findings reveal that $40 \%$ of the original research adopted the use of Geographic information system (GIS) techniques to analyze the potential of mangroves and wetlands in different areas, especially within the context of the urban setting. Also, other papers analyze the trend in the deterioration of essential coastal ecosystems and how they contributed to the increasing impact of the disaster, they further recommend the needs for replantation, conservation, and sustainable management of wetland and mangroves at those study locations. Due to the threats on mangroves in China, they conducted 
mangrove suitability assessments via GIS revealing 16,800 ha of area with the potential for mangrove restoration (Li et al., 2021).

To prove the essentiality of the coastal ecosystem (i.e wetland) in reducing the disaster impact. Bousquin et al., 2019 analyze how wetland reduces flood risk vulnerability, they use geospatial technology to analyze which region of the study area benefits from reduced flood risk through existing wetlands. Their findings validate the potential of the wetlands ecosystem in reducing flood damages by attenuating surface water in some parts of the United States.

(Wang et al., 2012) research on how the deterioration of coastal ecosystem due to land-use changes (urbanization and mining) contributes to the disastrous impact of flood and droughts in Jilin, China between 1980-2007, they adopted geospatial techniques to analyze how the conversion of forested land, grassland, wetland to arable land (mainly the dryland) brought about some negative effects (flood disasters) on the local environment over the years. They recommended the reforestation of mangroves and wetlands to minimize future coastal hazards.

\subsubsection{Degradation of Blue Carbon Ecosystems}

Degradation of blue carbon ecosystems is a common phenomenon in coastal areas around the world, with an annual global decline rate of 1-2\% (Karanja et al,. 2018). In addition to the global threat this poses to human and environmental security through the release of carbon, degradation of blue carbon ecosystems also poses an immediate threat at local scales because it exposes people, property and land to flood-related hazards. Mendez et al estimate that around the world, mangroves shield over 15 million people from floods (Menéndez et al., 2020). The primary cause of this degradation worldwide is land-use change, as mangroves and salt marshes are cleared and developed into urban and peri-urban areas or converted into agricultural land for growing crops or grazing livestock (Phethi et al., 2019). Urban replacement of blue carbon ecosystems also further increases flood risk by sealing and altering natural drainage characteristics (Gupta et al., 2011). Additional factors such as climate change, rising sea level, severe weather events, and pollution also contribute to the deterioration of these ecosystems.

Several of the case studies in this review investigated the scale and consequences of blue carbon ecosystem degradation in local, regional, and national contexts. A study of Bangalore and Chennai, India explored the relationship between rapid, extreme urbanization, wetland decline, and urban flooding. Between 1993 and 2007, built-up area in Bangalore increased by 466\% resulting in a decrease of wetlands from 51 to 17, which has contributed to increased flooding via a "loss of natural flood storage" and drainage obstruction (Gupta et al., 2011). Through a spatiotemporal analysis, Isunju et al. found that the Nakivubo wetland in Kampala, Uganda experienced a $62 \%$ reduction in wetland vegetation between 2002 and 2014 primarily due to increased crop cultivation (Isunju et al., 2016). This increased risk of flooding both by compromising the ecological flood buffer and by bringing more people and property into hazard-exposed areas. These community-level consequences of blue carbon ecosystem degradation underscore the direct benefit that these ecosystems have for people and their communities. 


\subsubsection{Sustainable Land Management: Conservation vs. Restoration vs. Establishment}

In response to these trends of degradation and their associated consequences in disaster risk, many documents in this review highlighted the need for policies, organizations, and communities to focus on sustainable land management practices through the conservation of existing ecosystems, the restoration of degraded ecosystems, and the establishment of new blue carbon ecosystems. Conservation is often considered the ideal method because it requires fewer interventions and is, therefore, less cost-intensive and more likely to succeed than restoration and establishment, as restoration efforts have historically had low success rates (Balke et al., 2016). Some studies also found conserved ecosystems to be more effective at disaster risk reduction than restored and newly established ecosystems (Menéndez et al., 2020).

However, restoration is still a key and necessary component of Eco-DRR land management strategies in blue carbon ecosystems because historic and ongoing degradation have left many populations and structures exposed to flooding without natural protection through healthy blue carbon ecosystems. When conservation is no longer an option, restoration efforts are necessary to enable natural ecosystem-based flood protection. A study of four countries in East Africa found that this was the case in many of the "priority concern districts" in which socio-economic vulnerability was high. To protect these districts, a combination of conservation and restoration was necessary to maximize flood protection (Ballesteros et al., 2021).

Though less common and even more challenging than restoration, some publications did discuss methods to establish new mangroves as ecosystem-based adaptation methods to flooding through green and hybrid infrastructure engineering (Takagi, 2019).

\subsubsection{Economics Value Assessment of Blue Carbon Ecosystems}

As sustainable management of coastal ecosystems is a key component to coastal disaster risk reduction, it is necessary to quantify the value of blue carbon ecosystems and their associated services in order to facilitate the protection of public and private entities in coastal regions. This quantification of the economic values of the blue carbon ecosystem will foster more opportunities for public-private cooperation in conservation and sustainable use of blue carbon ecosystems (Menéndez et al., 2020). Menéndez et al., 2020 researched the economic value of flood prevention enabled by coastal wetlands and mangroves in the Philippines, revealing that the presence of mangroves provides roughly 1 Billion US\$ annual savings and protects 613,461 people from flood hazards (Menéndez et al., 2020). Narayan et al., 2017 research findings similarly reveal that through flood reduction, coastal wetlands prevented over $\$ 625$ Million (USD) in flood damages throughout in 12 coastal states which Hurricane Sandy struck in 2012 (Narayan et al., 2017). 
Additionally, numerous researchers have studied the low cost of adopting coastal ecosystems in comparison to "gray infrastructure" like seawalls and coastal dikes. While the construction of coastal dikes is one of the methods that can be implemented to mitigate future tsunamis, this type of solution is often not possible in developing countries due to financial constraints (Takagi, 2019). In order to avoid the high cost that accrues from adopting hard engineering, countries can take the advantage of adopting coastal ecosystem solutions which are more cost-effective (Takagi, 2019). Natural methods that rely on sustainable management of blue carbon ecosystems combined with other buffers like sand dunes and coral reefs require minimal capital investment in contrast to the artificial measures (Tanaka, 2009). These ecosystem-based adaptations also have co-benefits of enhancing network relationships with surrounding ecological systems and providing recreational spaces in the form of beach fronts (Tanaka, 2009).

Despite the fact researchers have a relatively strong understanding of the relationship between coastal hazards and coastal ecosystems, there is still only a small body of research on the economic value of coastal ecosystem solutions as an Eco-DRR method (Boutwell et al., 2016). Based on this backdrop, there is a need for more research that analyzes the economic value of adopting coastal ecosystems solutions such as wetland, mangroves and seagrass.

\subsubsection{Policy Suggestions and Implications}

Intentionally directed, science-based policy is a necessary component to the sustainable management of blue carbon ecosystems, which is evidenced by the widespread degradation of blue carbon ecosystems when unrestricted and unmonitored. The policy suggestions made in this body of research were directed toward urban planners, environmental managers, disaster risk reduction practitioners, and governmental units at various levels.

Many researchers suggest the need to establish national systems and governmental bodies responsible for monitoring, improving and maintaining protective coastal ecosystems and for enforcing protective policies. Luo et al. 2015 emphasized the need for China to establish a coastal erosion management system as well as decision-makers and stakeholders who manage the tension between environmental and economic needs (Luo et al., 2015). In a study on wetlands in the United States, Endter-Wada et al. stressed the need for policy innovation to combat the repercussions of wetland degradation, and therefore suggested a national wetland commissions to "strategically link wetland protection to other societal objectives, including human disaster risk planning, infrastructure investments, and climate adaptation strategies," (Endter-Wada et al., 2020). This focus on standardized and well-conducted national policies often results from a historical lack of appropriate policies and law enforcement (Quevedo et al., 2020).

Specific, non-standardized policy suggestions and implications vary by nation, region, and locality, because the dynamics and histories of each ecosystem are unique, as are dynamics of the societies connected to those ecosystems. Therefore, decision makers should construct policies grounded in an awareness of local economies, political systems, and environmental landscape and processes (Douglas, 2018). An example of a situationally grounded recommendation came out of a study in Limpopo, South 
Africa, which assessed wetland degradation, determined that the primary cause was agricultural encroachment, and offered two suggestions; 1 ) fence off wetland areas to prevent further encroachment; 2) promote education initiatives to teach residents about the importance of the wetlands for the safety of themselves and their communities (Phethi et al., 2019). More locally informed and specific research is needed to offer practical and effective policy suggestions to coastal ecosystem adjacent communities around the world.

\subsection{Leximancer Concept Map}

The Leximancer analysis provided some key insights into the texts that support, and contribute to those identified in the thorough reading and coding process. Leximancer generated a frequency count of the 118 identified terms and a map diagramming how these key terms cluster and relate to each other throughout the documents in this review. The most common terms were 'coastal', used 1861 times, 'mangrove', used 1629 times, and 'flood' used 1589 times. The two layers of the concept map show linkages between related terms, seen in Figure 10, and twelve central concepts around which terms cluster, seen in Figure 11. Both the size of the grey dots representing the term and the size of the colored circles representing the central concepts correlate to the frequency with which they appear in the texts.

From left to right the map transitions gradually from concepts and terms focussed on earth-systems science, such as 'vegetation' and 'wave', to those focussed on human and societal systems, such as 'economic', 'urban' and 'development'. The terms and concepts in the center of the diagram show how earth system science and human systems are connected throughout the reviewed literature. For instance, the concept 'risk' and its associated terms like 'exposure', 'reduction', 'communities' and 'disaster' provide a link between the 'coastal' and 'economic' concepts.

Though this literature review focuses on the role of blue carbon ecosystems in disaster risk reduction, this analysis interestingly did not identify 'blue' or 'carbon' as regularly occurring terms. Many of the papers referred instead to types of blue carbon ecosystems such as 'mangroves' and 'salt marshes'. Rather than a research gap, this indicates an inconsistency in nomenclature across disciplines and geographies. Any review of blue carbon should also consider terms that indicate blue carbon ecosystems but may not be specifically referred to as such. Similarly, it is possible that other core concepts may not appear in the Leximancer analysis due to inconsistent nomenclature.

\subsection{Discussion}

This review shows that blue carbon ecosystems have a dual utility in improving human security through carbon sequestration, which contributes to climate change mitigation and coastal risk reduction. The analysis illuminates the current state of literature, recurring themes and trends, and gaps in the knowledge surrounding blue carbon ecosystems as Eco-DRR measures. A major limitation of the review is that it only assesses scientifically published studies though it is likely that significant discussion among planners, policy makers, stakeholders and decision makers occurs in other settings like project reports and policy briefs. However, a foundation of scientifically grounded research is also necessary for 
such practical applications, so a literature review focussing exclusively on scientifically published studies is both necessary and relevant. Another limitation is the wide variety nomenclature surrounding both blue carbon ecosystems and Eco-DRR, which may have resulted in the neglect of related terms from our Web of Science query. However, as the selected terms were prepared based on key terms found in scientific literature, they did reveal a detailed collection of publications that provide valuable insight into the subject.

While the majority of papers held positive perspectives on the role of blue carbon ecosystems in disaster risk reduction, some were critical of the capacity of such ecosystems to combat severe incidents like typhoons and tsunamis. Though blue carbon ecosystems do have the capacity to diminish waves and storm surges, researchers warn that these systems do have thresholds that severe impacts may exceed, leading to failure and even collapse of the ecosystems (Gijsman et al. 2020).

The advancement in Geospatial techniques paved the way for the use of GIS in analyzing the potential of mangroves and wetlands as one of the Eco-based solutions for reducing coastal hazards. GIS has therefore been used to assess the state of blue carbon ecosystems on global and local scales, revealing both successful and potential blue carbon ecosystems (Jones et al., 2020). Some of the reviewed papers used GIS techniques to analyze the impact of flood disasters on areas with no ecosystem compared to areas with the presence of mangroves and wetlands. This proves the synergies of Blue carbon as the element of Eco-DRR and seeks future research to assess the real-time changes or deterioration of mangroves, wetlands and salt marshes.

Sustainable Land Management, informed by scientific research, is central in ensuring the continued success of existing blue carbon ecosystems and creating possibilities for renewed flourishing of such ecosystems. Among researchers, there is a hierarchy of strategies with conservation being preferred, followed by restoration, then establishment of new blue carbon ecosystems. However, when critical wetlands, mangroves, salt marshes, and seagrasses have been depleted, restoration is a necessary means to protecting poeple, property, and ecologies. Understanding why ecosystems have been degraded is a key component to understanding how they can be restored. A wider body of locally specific knowledge is necessary in this persuit.

The global distribution of national, regional, and local studies investigating blue carbon ecosystems in disaster risk reduction is a crucial research gap that is relevant to each of the themes explored in the textual analysis: GIS analysis; ecosystem degradation; sustainable land management; economic value assessments; and policy suggestions. This review only revealed case studies in sixteen countries, with significant clusters in the United States and East and Southeast Asia. In contrast, no studies took place in South America, a continent with only two land-locked countries. This poses a significant problem to a complete understanding of blue carbon ecosystems, because they vary greatly due to unique local environmental processes and systems and distinct local histories. There is also a broad scope of interactions and relationships that humans and societies have with wetlands, based on cultural values and utilized ecosystem services. It is neither necessary nor possible to compile a comprehensive body of 
research examining every combination of these factors. However, a more detailed catalogue is necessary when applying concepts to new locations. For instance, the driving factors for coastal ecosystem degradation vary from place and range from agricultural and industrial runoff, land-use change, unsanctioned livelihood activities, invasive species, or a combination thereof. These factors can be tied to culture and ecology specific to certain regions or countries. Therefore, when policy makers look to research, to inform decisions, locally relevant research is necessary.

\subsection{Conclusion}

Blue carbon ecosystems not only have the capacity to mitigate climate change, but also to reduce the risk of disasters related to coastal hazards. In this paper, we investigated the role of blue carbon as an ecosystem disaster risk reduction method by examining the state of various academic literature that addressed both Eco-DRR and blue carbon ecosystems. Some of the literature adopted geospatial techniques as a tool to explain the trend in the deterioration of coastal ecosystems (mangrove, wetland, and salt marshes). They reveal the scale and consequence of blue carbon ecosystem degradation in local, regional, national context and how their absence can contribute to an increasing impact of the disaster. We conclude that the community-level consequences of blue carbon ecosystem degradation underscore the direct benefit that these ecosystems have for people and their communities.

Several studies also explained blue carbon ecosystems to be a more effective method to mitigate and reduce coastal hazards, emphasizing the need for restoration and conservation of blue carbon ecosystems such as mangroves, salt marshes, and wetlands. Quantifying the economic values of the blue carbon ecosystem will foster more opportunities for public-private cooperation in the conservation and sustainable use of blue carbon ecosystems (Menendez et al., 2020). Therefore, we recommend future research on the quantification of the benefit of blue carbon in reducing coastal hazards.

Finally, we also recommend continued efforts and research in wide-spread sustainable management of wetland and mangroves via conservation and replantation. Additionally, we recommended the need for policies, organizations, and communities to focus on sustainable ocean resource management practices through the conservation of existing coastal ecosystems, the restoration of degraded ecosystems, and the establishment of new blue carbon ecosystems.

\section{Declarations}

Funding: The authors received no specific funding for this work.

Conflict of Interest: The authors declare no conflict of interests.

Data Availability: The datasets generated and analyzed during the current study are available from the corresponding author on reasonable request.

\section{Authors Contribution:}


Taiwo Ogunwumi wrote the Background introduction, Concept definition, Maps and charts and Conclusion while Maggie Armstrong wrote the Methodology, Result (Data analysis), Leximancer Concept map. Both authors reviewed all the selected literature and wrote the Literature Synthesis, Discussion. Both author reviewed the manuscript.

\section{References}

1. Acreman, M., \& Holden, J. (2013). How wetlands affect floods. Wetlands, 33(5), 773-786.

2. Balke, T., \& Friess, D. A. (2016). Geomorphic knowledge for mangrove restoration: a pan-tropical categorization. Earth Surface Processes and Landforms, 41(2), 231-239.

3. Ballesteros, C., \& Esteves, L. S. (2021). Integrated Assessment of Coastal Exposure and Social Vulnerability to Coastal Hazards in East Africa. Estuaries and Coasts, 1-17.

4. Barbier, E. B. (2006). Natural barriers to natural disasters: replanting mangroves after the tsunami. Frontiers in Ecology and the Environment, 4(3), 124-131.

5. Bertram, C., Quaas, M., Reusch, T. B., Vafeidis, A. T., Wolff, C., \& Rickels, W. (2021). The blue carbon wealth of nations. Nature Climate Change, 11(8), 704-709.

6. Blue carbon initiative, (2010). Mitigating Climate Change through Coastal Ecosystem Management (Last accessed: September 2021) https://www.thebluecarboninitiative.org/

7. Bousquin, J., \& Hychka, K. (2019). A geospatial assessment of flood vulnerability reduction by freshwater wetlands-a benefit indicators approach. Frontiers in Environmental Science, 7, 54.

8. Boutwell, J. L., \& Westra, J. V. (2016). The role of wetlands for mitigating economic damage from hurricanes. JAWRA Journal of the American Water Resources Association, 52(6), 1472-1481.

9. Campbell, A., V. Kapos, J.P.W. Scharlemann, P. Bubb, A. Chenery, L. Coad, B. Dickson, N. Doswald, M.S.I. Khan, F. Kershaw and M. Rashid (2009) Review of the Literature on the Links between Biodiversity and Climate Change: Impacts, Adaptation and Mitigation. Secretariat of the Convention on Biological Diversity, Technical series 42 .

10. Chmura, G. L., Anisfeld, S. C., Cahoon, D. R., \& Lynch, J. C. (2003). Global carbon sequestration in tidal, saline wetland soils. Global biogeochemical cycles, 17(4). https://doi.org/10.1029/2002GB001917

11. Cochard, R., Ranamukhaarachchi, S. L., Shivakoti, G. P., Shipin, O. V., Edwards, P. J., \& Seeland, K. T. (2008). The 2004 tsunami in Aceh and Southern Thailand: a review on coastal ecosystems, wave hazards and vulnerability. Perspectives in Plant Ecology, Evolution and Systematics, 10(1), 3-40.

12. Donato, D., Kauffman, J., Murdiyarso, D. et al. Mangroves among the most carbon-rich forests in the tropics. Nature Geosci 4, 293-297 (2011). https://doi.org/10.1038/ngeo1123 
13. Douglas, I. (2018). The challenge of urban poverty for the use of green infrastructure on floodplains and wetlands to reduce flood impacts in intertropical Africa. Landscape and Urban Planning, 180, 262272.

14. Endter-Wada, J., Kettenring, K. M., \& Sutton-Grier, A. (2020). Protecting wetlands for people: Strategic policy action can help wetlands mitigate risks and enhance resilience. Environmental Science \& Policy, 108, 37-44.

15. Estrella, M. \& Saalismaa, N. The Role of Ecosystem Management in Disaster Risk Reduction (eds Renaud, F. et al.) 30-31 (UNU Press, 2013).

16. Gijsman, R., Horstman, E. M., van der Wal, D., Friess, D. A., Swales, A., \& Wijnberg, K. M. (2021). Naturebased engineering: a review on reducing coastal flood risk with mangroves. Frontiers in Marine Science, 8 , 825.

17. Giri, C., Ochieng, E., Tieszen, L. L., Zhu, Z., Singh, A., Loveland, T., ... \& Duke, N. (2011). Status and distribution of mangrove forests of the world using earth observation satellite data. Global Ecology and Biogeography, 20(1), 154-159. (2011): 154-159.

18. Grimsditch, G., Alder, J., Nakamura, T., Kenchington, R., Tamelander, J., (2013). The blue carbon special edition - introduction and overview. Ocean Coast. Manag. 83, 1-4. https://www.sciencedirect.com/science/article/pii/S0964569112000981?via\%3Dihub

19. Grist, 2021. The U.K.'s lost seagrass meadows to be resurrected in the climate fight. https://grist.org/climate/the-u-k-s-lost-seagrass-meadows-to-be-resurrected-in-climate-fight/

20. Guo, M.; Li, J.; Sheng, C.; Xu, J.; Wu, L. (2017) A Review of Wetland Remote Sensing. Sensors 2017, 17, 777. https://doi.org/10.3390/s17040777

21. Gupta, A. K., \& Nair, S. S. (2011). Urban floods in Bangalore and Chennai: risk management challenges and lessons for sustainable urban ecology. Current Science, 1638-1645.

22. Hu, W., Wang, Y., Zhang, D., Yu, W., Chen, G., Xie, T., ... \& Chen, B. (2020). Mapping the potential of mangrove forest restoration based on species distribution models: A case study in China. Science of The Total Environment, 748, 142321.

23. Huang, Y., Zhang, T., Wu, W., Zhou, Y., \& Tian, B. (2017). Rapid risk assessment of wetland degradation and loss in low-lying coastal zone of Shanghai, China. Human and Ecological Risk Assessment: An International Journal, 23(1), 82-97.

24. Isunju, J. B., \& Kemp, J. (2016). Spatiotemporal analysis of encroachment on wetlands: a case of Nakivubo wetland in Kampala, Uganda. Environmental monitoring and assessment, 188(4), 203. 
25. IUCN, 2021. Mangroves and coastal ecosystems. https://www.iucn.org/theme/marine-and-polar/ourwork/climate-change-and-ocean/mangroves-and-coastal-ecosystems

26. J. Siikamäki, J. Sanchirico, S. Jardine, D. McLaughlin, and D. Morris, Blue Carbon: Global Options for Reducing Emissions from the Degradation and Development of Coastal Ecosystems, RFF Report (November 2012).

27. Jones, H. P., Nickel, B., Srebotnjak, T., Turner, W., Gonzalez-Roglich, M., Zavaleta, E., \& Hole, D. G. (2020). Global hotspots for coastal ecosystem-based adaptation. PloS one, 15(5), e0233005.

28. Juha Siikamäki, James N. Sanchirico, Sunny Jardine, David McLaughlin \& Daniel Morris (2013). Blue Carbon: Coastal Ecosystems, Their Carbon Storage, and Potential for Reducing Emissions, Environment: Science and Policy for Sustainable Development, 55:6, 14-29, DOI:

$10.1080 / 00139157.2013 .843981$

29. Karanja, J. M., \& Saito, O. (2018). Cost-benefit analysis of mangrove ecosystems in flood risk reduction: a case study of the Tana Delta, Kenya. Sustainability Science, 13(2), 503-516.

30. Lathrop Jr, R. G., Irving, W., Seneca, J. J., Trimble, J., \& Sacatelli, R. M. (2019). The limited role salt marshes may have in buffering extreme storm surge events: Case study on the New Jersey shore. Ocean \& Coastal Management, 178, 104803.

31. Leximancer, (2021). "Leximancer User Guide Release 4.5”. http://info.leximancer.com (Last accessed: September 15,2021$)$

32. Leonardi, N., Carnacina, I., Donatelli, C., Ganju, N. K., Plater, A. J., Schuerch, M., \& Temmerman, S. (2018). Dynamic interactions between coastal storms and salt marshes: A review. Geomorphology, 301, 92-107.

33. Li, W., Jiang, Y., Duan, Y., Bai, J., Zhou, D., \& Ke, Y. (2021). Where and how to restore wetland by utilizing storm water at the regional scale: A case study of Fangshan, China. Ecological Indicators, 122, 107246.

34. Luo, S., Cai, F., Liu, H., Lei, G., Qi, H., \& Su, X. (2015). Adaptive measures adopted for risk reduction of coastal erosion in the People's Republic of China. Ocean \& Coastal Management, 103, 134-145.

35. Mcleod, E., Chmura, G.L., Bouillon, S., Salm, R., Björk, M., Duarte, C.M., Lovelock, C.E., Schlesinger, W.H., Silliman, B.R., (2011). A blueprint for blue carbon: toward an improved understanding of the role of vegetated coastal habitats in sequestering CO2. Front. Ecol. Environ. 9 (10), 552-560. https://esajournals.onlinelibrary.wiley.com/doi/abs/10.1890/110004

36. Mcowen, Chris; Weatherdon, Lauren; Bochove, Jan-Willem; Sullivan, Emma; Blyth, Simon; Zockler, Christoph; Stanwell-Smith, Damon; Kingston, Naomi; Martin, Corinne (21 March 2017). "A global map of saltmarshes". Biodiversity Data Journal. 5 (5): e11764. doi:10.3897/bdj.5.e11764 
37. Menendez, P., Losada, I. J., Beck, M. W., Torres-Ortega, S., Espejo, A., Narayan, S., ... \& Lange, G. M. (2018). Valuing the protection services of mangroves at national scale: The Philippines. Ecosystem services, 34, 24-36.

38. Menéndez, P., Losada, I. J., Torres-Ortega, S., Narayan, S., \& Beck, M. W. (2020). The global flood protection benefits of mangroves. Scientific reports, 10(1), 1-11.

39. Möller, I. (2019). Applying uncertain science to nature-based coastal protection: lessons from shallow wetland-dominated shores. Frontiers in Environmental Science, 7, 49.

40. Narayan, S., Beck, M. W., Wilson, P., Thomas, C. J., Guerrero, A., Shepard, C. C., ... \& Trespalacios, D. (2017). The value of coastal wetlands for flood damage reduction in the northeastern USA. Scientific reports, $7(1), 1-12$.

41. National Oceanic and Atmospheric Administration (NOAA), 2021. "What is a wetland" https://oceanservice.noaa.gov/facts/wetland.html (Last Accessed September 2021)

42. Nellemann, C., Corcoran, E., Duarte, C.M., Valdés, L., DeYoung, C., Fonseca, L., Grimsditch, G., (2009). Blue Carbon. A Rapid Response Assessment. United Nations Environment Programme, GRID-Arendal (Available at http://www.grida.no). This report was the first to use the term "blue carbon".

43. Osawa, T., Nishida, T., \& Oka, T. (2020). High tolerance land use against flood disasters: How paddy fields as previously natural wetland inhibit the occurrence of floods. Ecological Indicators, 114, 106306.

44. Pendleton L, Donato DC, Murray BC, Crooks S, Jenkins WA, Sifleet S, et al. (2012) Estimating Global “Blue Carbon" Emissions from Conversion and Degradation of Vegetated Coastal Ecosystems. PLoS ONE 7(9): e43542. https://doi.org/10.1371/journal.pone.0043542

45. Phethi, M. D., \& Gumbo, J. R. (2019). Assessment of impact of land use change on the wetland in Makhitha village, Limpopo province, South Africa. Jamba: Journal of Disaster Risk Studies, 11(2), 1-6.

46. Potenski, M (2021). Blue Carbon. https://www.marineconservation.org.au/blue-carbon/

47. Quevedo, J. M. D., Uchiyama, Y., \& Kohsaka, R. (2021). Community perceptions of long-term mangrove cover changes and its drivers from a typhoon-prone province in the Philippines. Ambio, 1-18.

48. Reguero, B. G., Beck, M. W., Bresch, D. N., Calil, J., \& Meliane, I. (2018). Comparing the cost effectiveness of nature-based and coastal adaptation: A case study from the Gulf Coast of the United States. PloS one, 13(4), e0192132.

49. Ruckelshaus, M., Reguero, B. G., Arkema, K., Compeán, R. G., Weekes, K., Bailey, A., \& Silver, J. (2020). Harnessing new data technologies for nature-based solutions in assessing and managing risk in coastal zones. International Journal of Disaster Risk Reduction, 51, 101795. 
50. Saleh, F., \& Weinstein, M. P. (2016). The role of nature-based infrastructure (NBI) in coastal resiliency planning: A literature review. Journal of Environmental Management, 183, 1088-1098.

51. Shepard, C. C., Crain, C. M., \& Beck, M. W. (2011). The protective role of coastal marshes: a systematic review and meta-analysis. PloS one, 6(11), e27374.

52. Shepard, C. C., Crain, C. M., \& Beck, M. W. (2011). The protective role of coastal marshes: a systematic review and meta-analysis. PloS one, 6(11), e27374.doi:10.1371/journal.pone.0027374.

53. Silver, J. M., Arkema, K. K., Griffın, R. M., Lashley, B., Lemay, M., Maldonado, S., ... \& Verutes, G. (2019). Advancing coastal risk reduction science and implementation by accounting for climate, ecosystems, and people. Frontiers in Marine Science, 6, 556.

54. Siverd, C. G., Hagen, S. C., Bilskie, M. V., Braud, D. H., \& Twilley, R. R. (2020). Quantifying storm surge and risk reduction costs: a case study for Lafitte, Louisiana. Climatic change, 161(1), 201-223.

55. Sudmeier-Rieux, K. and N. Ash (2009) Environmental Guidance Note for Disaster Risk Reduction: Healthy Ecosystems for Human Security. Ecosystem Management Series No. 8, Commission on Ecosystem Management, revised edition. Gland, Switzerland: IUCN.

56. Sutton-Grier, A.E., Moore, A.K., Wiley, P.C., Edwards, P.E.T., (2014). Incorporating ecosystem services into the implementation of existing US natural resource management regulations: operationalizing carbon sequestration and storage. Mar. Policy 43, 246-253.

https://www.sciencedirect.com/science/article/pii/S0308597X13001292

57. Tai, A., Hashimoto, A., Oba, T., Kawai, K., Otsuki, K., Nagasaka, H., \& Saita, T. (2015). Growth of mangrove forests and the influence on flood disaster at Amami Oshima Island, Japan. Journal of Disaster Research, 10(3), 486-494.

58. Takagi, H. (2019). "Adapted mangrove on hybrid platform"-Coupling of ecological and engineering principles against coastal hazards. Results in Engineering, 4, 100067.

59. Tanaka, N. (2009). Vegetation bioshields for tsunami mitigation: review of effectiveness, limitations, construction, and sustainable management. Landscape and Ecological Engineering, 5(1), 71-79.

60. The WildlifeTrust (2021) " Natural solutions to climate change" https://www.wildlifetrusts.org/naturalsolutions-climate-change/seagrass

61. The WildlifeTrust (2021) " Natural solutions to climate change" https://www.wildlifetrusts.org/naturalsolutions-climate-change/saltmarshes

62. TRACKVIA (2013). "Online database helps property owners manage wetlands" https://trackvia.com/blog/online-database-blog/online-database-helps-property-ownersmanage-wetlands/ 
63. UNEP (2020) "ECOSYSTEM-BASED DISASTER RISK REDUCTION"

postconflict.unep.ch/publications/EcoDRR_2pager.pdf (Last Accessed: September 2021)

64. UNEP-WCMC and F. T. Short, (2005) "Global Distribution of Seagrasses-Polygons Dataset," in WorldAtlas of Seagrasses. Available from UNEPWCMC Ocean Data Viewer, www.unep-wcmc.org (Last accessed September 15, 2021).

65. UNISDR (2009) Terminology on Disaster Risk Reduction". United Nations, Geneva. Available at <https://www.unisdr.org/files/7817_UNISDRTerminologyEnglish.pdf (last accessed 20 September 2021).

66. (USDA) United States Department of Agriculture and (NRCS) Natural Resources Conservation Service, (2005). https://plants.usda.gov/home

67. US Environmental Protection Agency. Ecosystem Services. Last updated on September 01, 2021. https://www.epa.gov/eco-research/ecosystem-services

68. Vazquez-Gonzalez, C., Moreno-Casasola, P., Peláez, L. A. P., Monroy, R., \& Espejel, I. (2019). The value of coastal wetland flood prevention lost to urbanization on the coastal plain of the Gulf of Mexico: An analysis of flood damage by hurricane impacts. International Journal of Disaster Risk Reduction, 37, 101180.

69. Vermaat, J. E., \& Thampanya, U. (2006). Mangroves mitigate tsunami damage: A further response. Estuarine, Coastal and Shelf Science, 69(1-2), 1-3.

70. Vuik, V., Borsje, B. W., Willemsen, P. W., \& Jonkman, S. N. (2019). Salt marshes for flood risk reduction: Quantifying long-term effectiveness and life-cycle costs. Ocean \& coastal management, 171, 96-110.

71. Wang, L., Long, H., Liu, H., \& Dong, G. (2012). Analysis of the Relationship between Drought-Flood Disasters and Land-Use Changes in West Jilin, China. Disaster Adv., 5(4), 652-658.

72. Wells, J. A., Wilson, K. A., Abram, N. K., Nunn, M., Gaveau, D. L., Runting, R. K., ... \& Meijaard, E. (2016). Rising floodwaters: mapping impacts and perceptions of flooding in Indonesian Borneo. Environmental Research Letters, 11(6), 064016.

\section{Figures}


A) Healthy Ecosystems and Nature-based Solutions

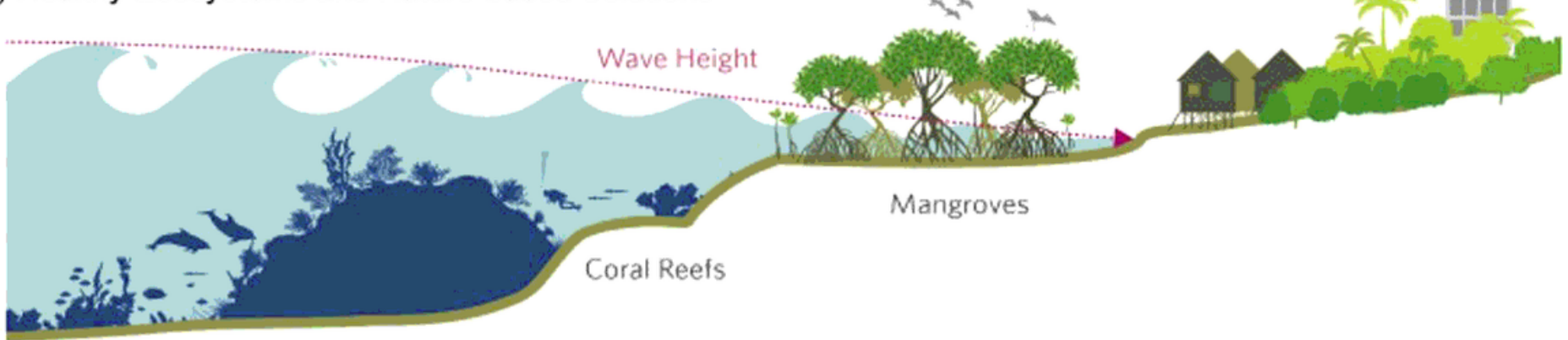

\section{B) Degraded ecosystems}

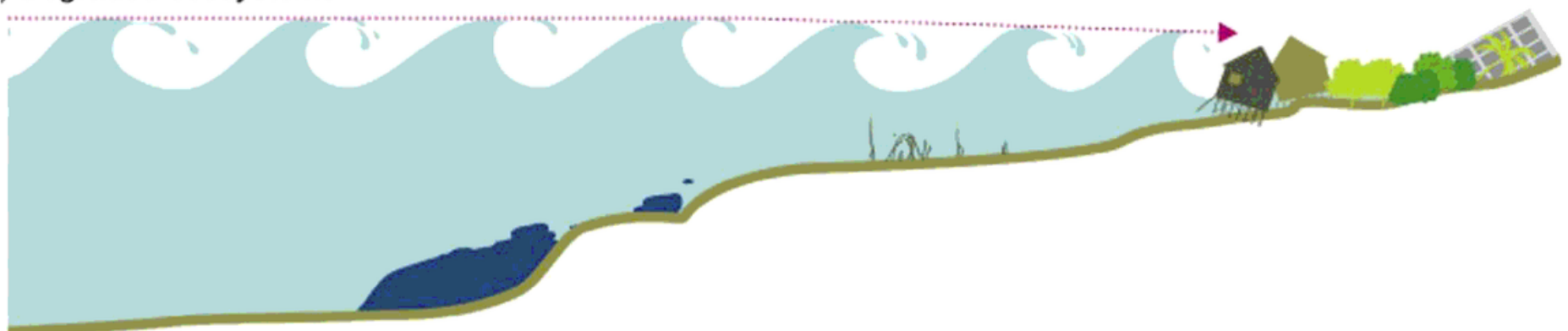

\section{Figure 1}

Graphic displaying the Eco-DRR services provided by healthy coastal ecosystems. These complex systems absorb and dissipate energy, resulting in decreased wave height and frequency, which in turn decreases the impact of the hazard on the human settlement. Source: Ruckelshaus et al., 2020.

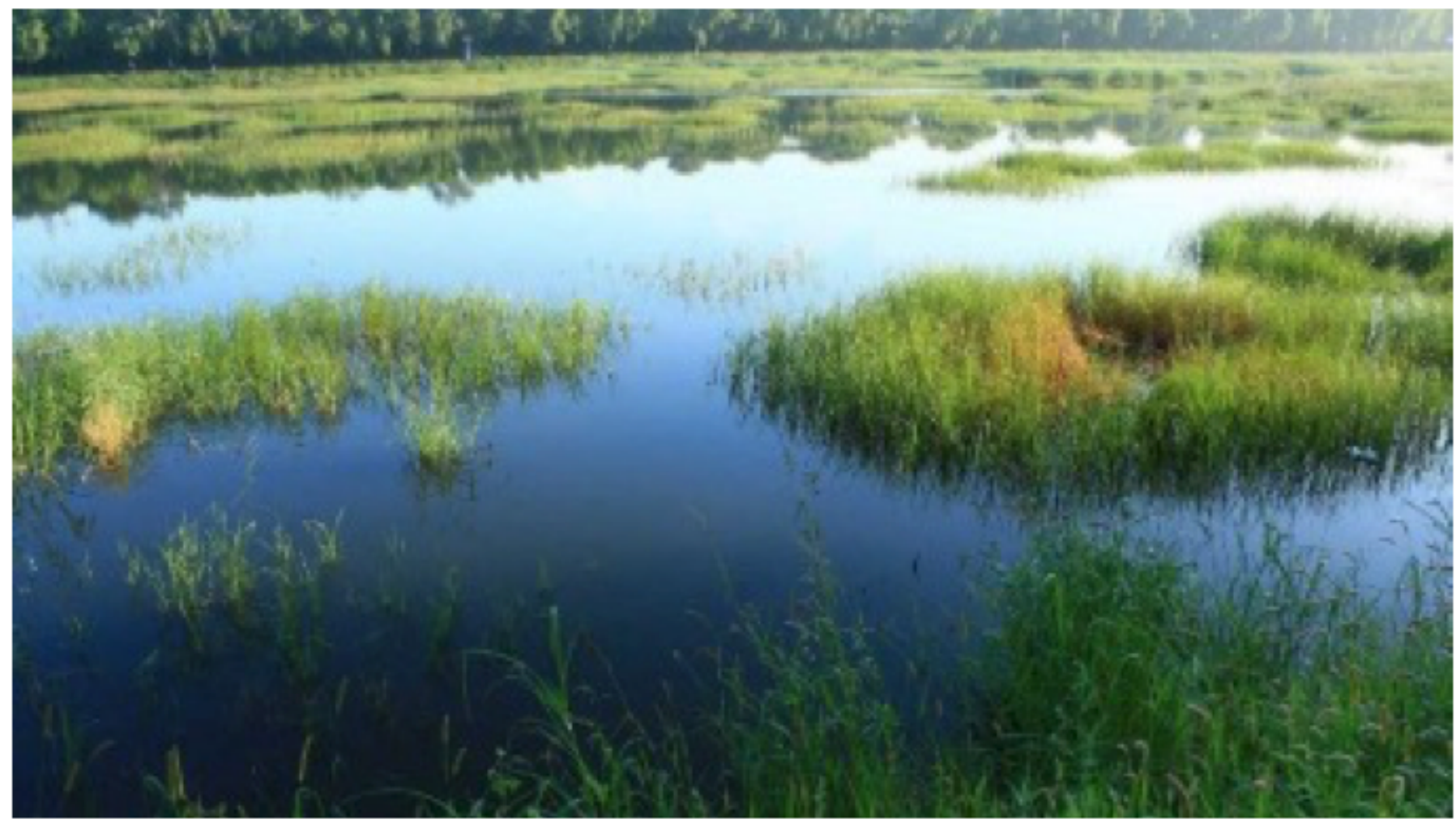


Figure 2

Wetland

Source: TRACKVIA,2013

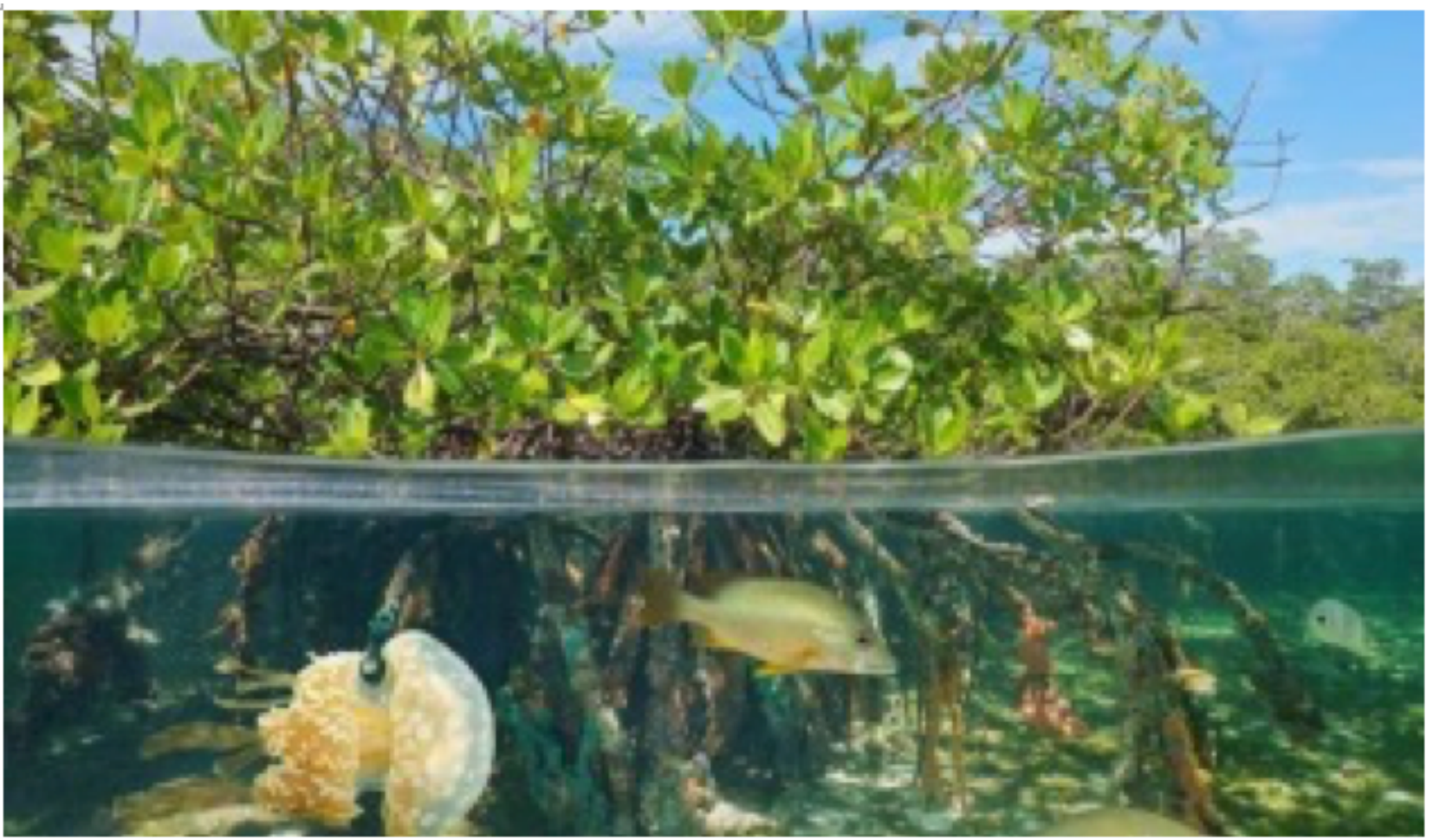

Figure 3

Mangrove oceanic tree root systems

Source: IUCN , 2021 


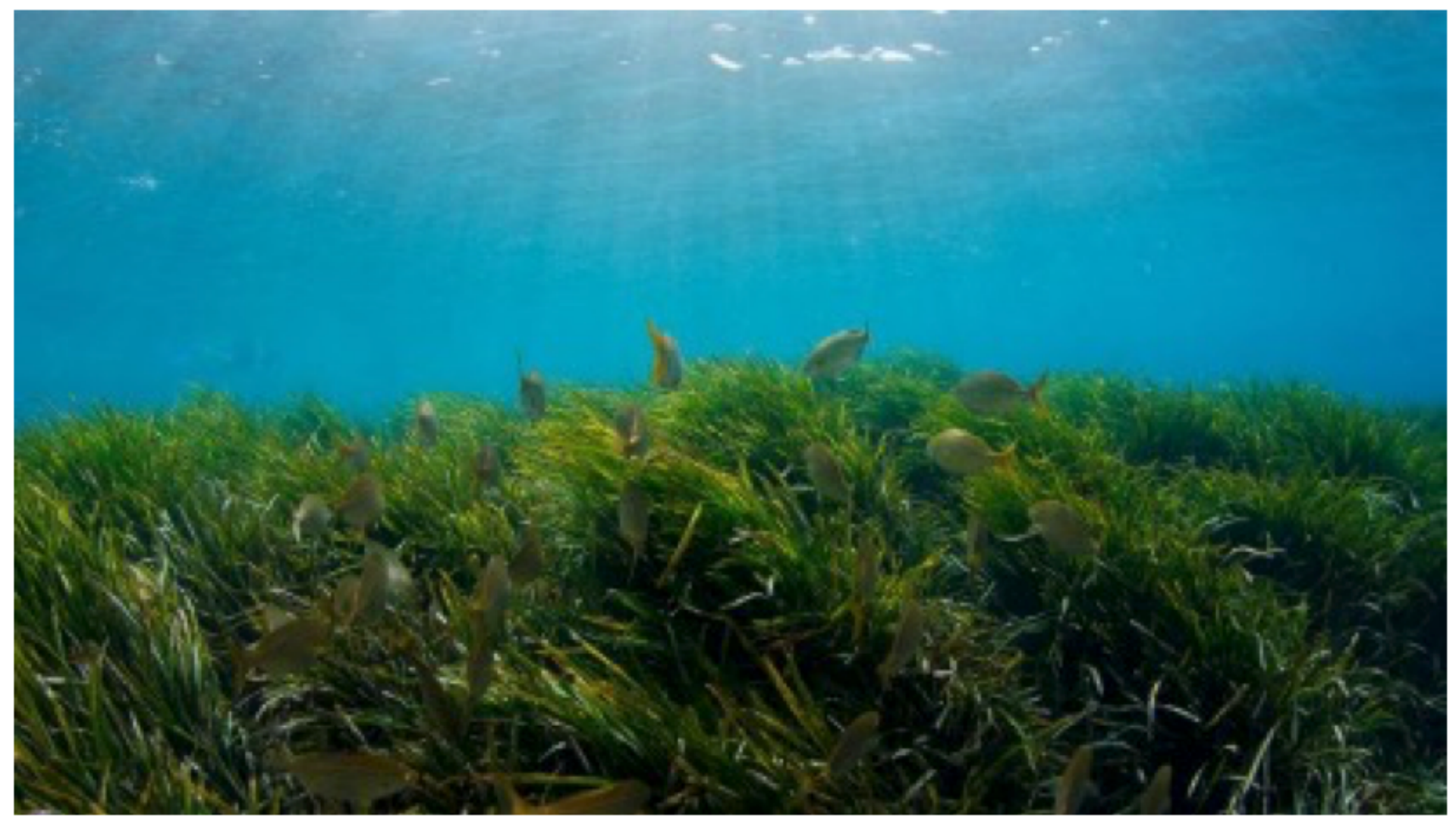

Figure 4

Seagrasses

Source: Grist, 2021 


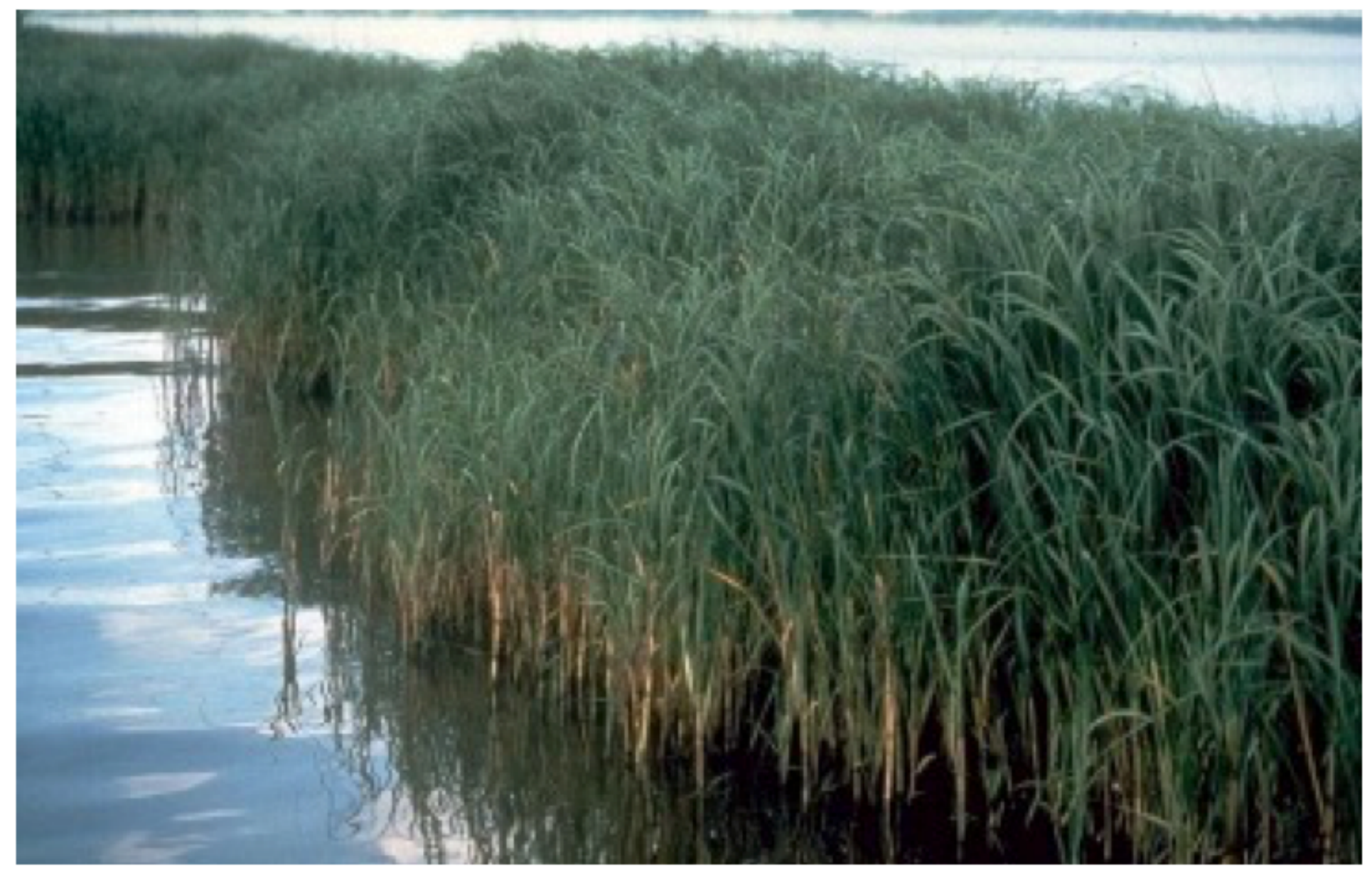

Figure 5

Salt Marshes (Spartina alterniflora)

Source: USDA NRCS PLANTS Database, 2005 


\section{Blue Carbon Ecosystems as Eco-DRR: Number of Studies per Country}

10208 No data
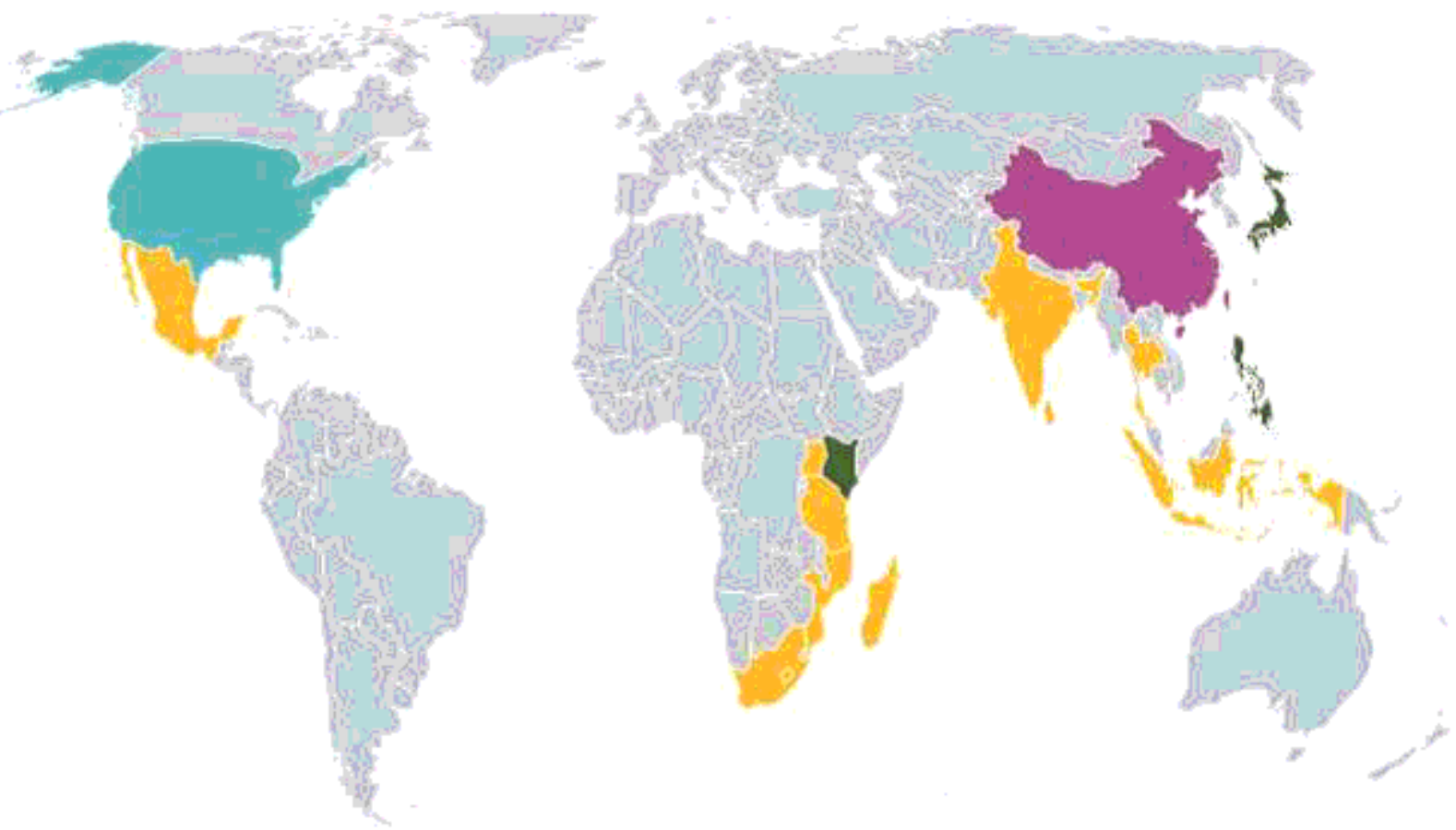

Figure 6

Map showing the number of research studies per country 


\section{Studies by Geographic Scale}

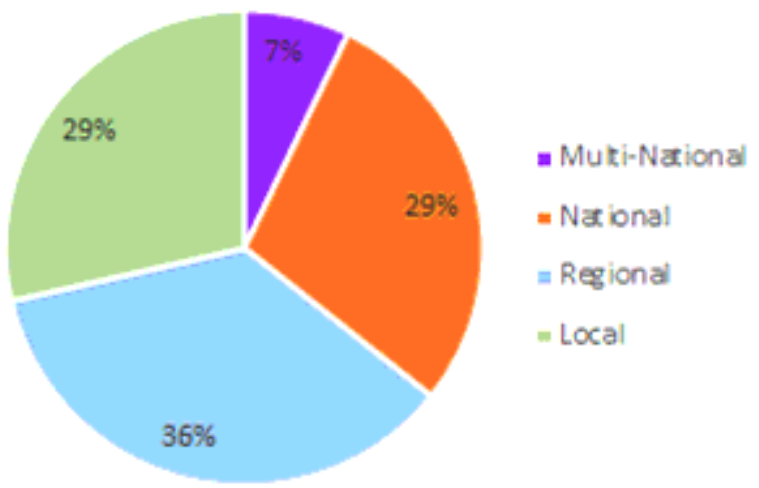

\section{Figure 7}

Chart showing the percentage of studies conducted at multinational, national, regional, and local levels

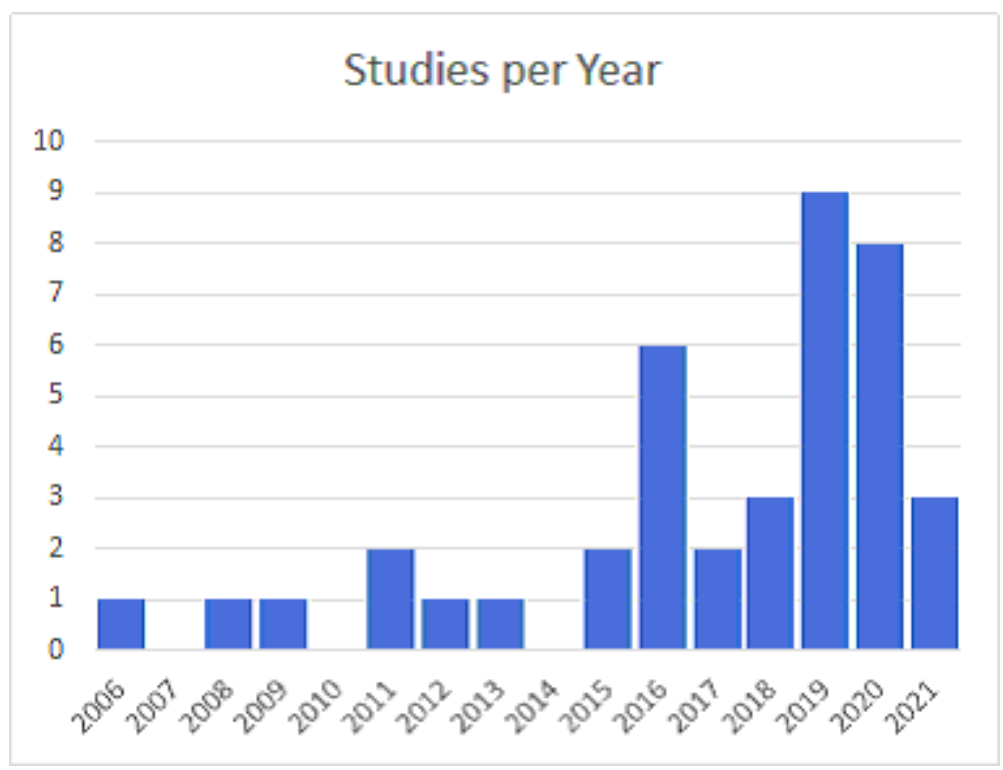

Figure 8

Chart showing the number of publications per year that addressed both blue carbon ecosystems and Eco DRR. 


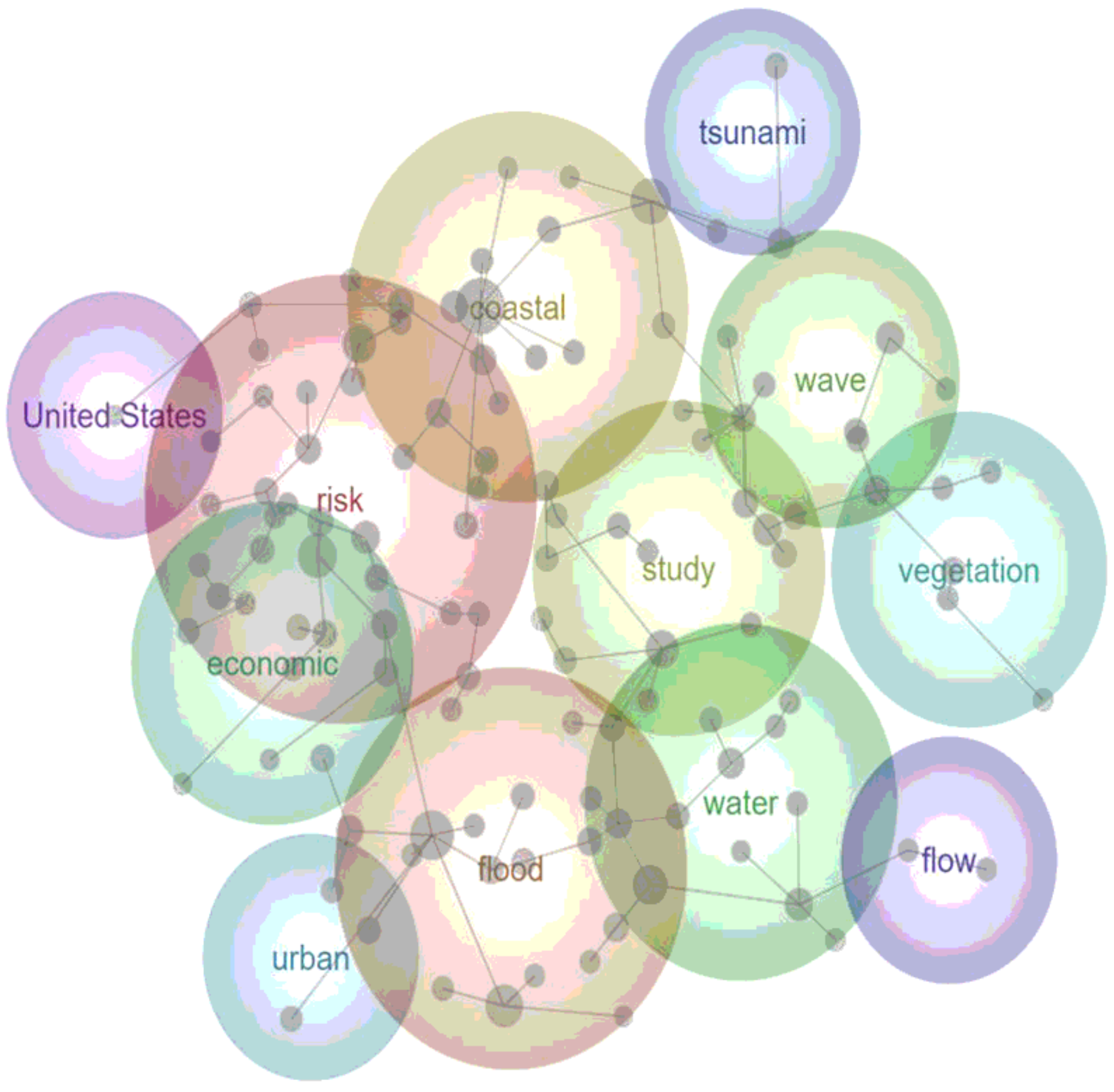

Figure 9

Leximancer Analysis Term Map: Map shows how the most common terms cluster and relate to each other. The size of the circles correlates to the frequency of use. 


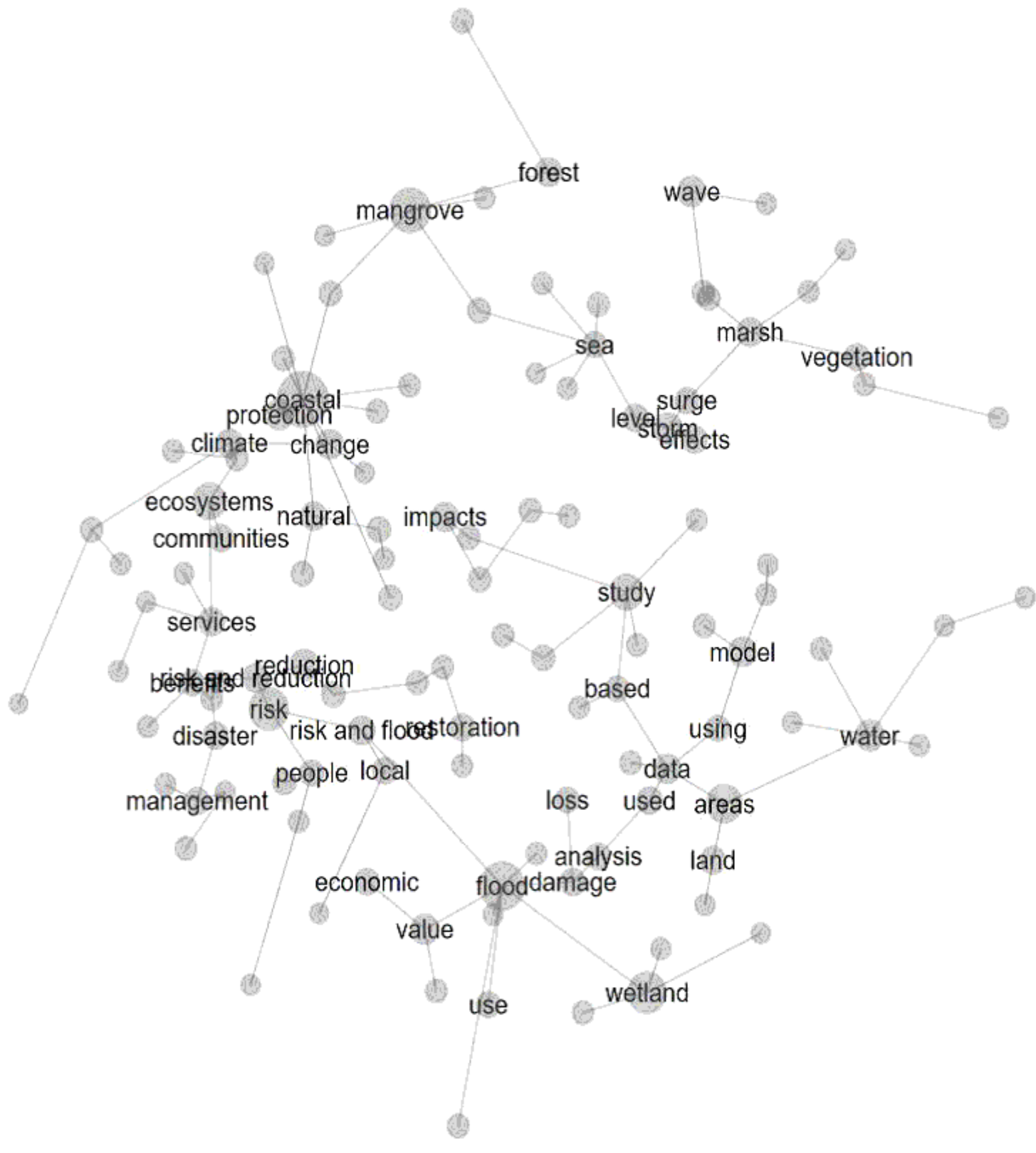

Figure 10

Leximancer Analysis Concept Map: Map that displays central concepts of the common terms. The size of the circles correlates to the frequency of the various terms.

\section{Supplementary Files}

This is a list of supplementary files associated with this preprint. Click to download. 
- Appendix.docx

Page 28/28 